\title{
DIFFERENTIATION OF SUBTYPES WITHIN LEPTOSPIRA INTERROGANS SEROVARS HARDJO,BALCANICA AND TARASSOVI, BY BACTERIAL RESTRICTION-ENDONUCLEASE DNA ANALYSIS (BRENDA)
}

\author{
A. J. Robinson, P. Ramadass, Alison Lee and R. B. Marshall \\ Department of Veterinary Pathology and Public Health, Massey University, \\ Palmerston North, New Zealand
}

\begin{abstract}
SUMmARY. Various strains of Leptospira interrogans were compared by bacterial restriction-endonuclease DNA analysis (BRENDA). Field strains of serovar hardjo isolated from domestic animals in New Zealand, Australia and Northern Ireland were indistinguishable from one another but differed strikingly from the hardjo reference strain Hardjoprajitno. Similarly, field isolates of balcanica and tarassovi differed from their serovar reference strains, probably owing to a difference in epidemiological niche. Subdivision of these serovars into distinct subtypes as defined by BRENDA is therefore useful and justified. In contrast, analysis of serovars pomona, ballum and copenhageni shows that field and reference strains were identical, or differed only by a single band.

It is suggested that BRENDA will overcome many of the problems associated with serological methods of identifying serovars and allow more precise definition of epidemiological relationships between strains and their hosts.
\end{abstract}

\section{INTRODUCTION}

All the leptospiral pathogens of mammals are considered to belong to the single species Leptospira interrogans. Within this species there are more than 130 different serovars each with its own pathological and epidemiological characters. As the name serovar suggests, identification has relied entirely upon serological methods. Marshall, Wilton and Robinson (1981) described a means of differentiating New Zealand field isolates of $L$. interrogans serovars hardjo and balcanica by restriction-endonuclease analysis of DNA, and suggested that this new method had advantages over serological testing. The DNA was extracted from a culture of the organism and digested with a restriction endonuclease, and the resulting fragments were separated by electrophoresis in an agarose gel. The DNA fragments in the gel were stained with ethidium bromide and examined under ultraviolet light. The pattern of bands produced could be used to identify the isolate. 
In this paper we describe the use of bacterial restriction-endonuclease DNA analysis (BRENDA) to compare strains of serovars hardjo and balcanica isolated from different parts of the world; and to compare reference strains of other serovars with field strains isolated in New Zealand.

\section{MATERIALS AND METHODS}

Bacterial strains. All strains (see table) had been identified by conventional serological methods.

Preparation of bacteriophage $\lambda D N A$. Bacteriophage C1857 S7 was made from a lysogenic strain of Escherichia coli by the method described by Miller (1972). The DNA was extracted by the method of Younghusband and Bellett (1971).

Bacterial DNA extraction, restriction-endonuclease digestion, gel electrophoresis, and photography. The methods have been described previously (Marshall et al., 1981). The restriction endonuclease $E c o R_{1}$ used in these experiments was prepared by the method of Tanaka and Weisblum (1975). The restriction endonucleases Bam H-1 and Hind III were from New England Biolabs, Beverly, MA 01915, USA. Digestions with Bam H-1 were made at $37^{\circ} \mathrm{C}$ for 1 $\mathrm{h}$ in $100 \mu \mathrm{l}$ of a solution containing $50 \mathrm{~mm} \mathrm{NaCl}, 6 \mathrm{~mm}$ TRIS- $\mathrm{HCl}(p \mathrm{H} \mathrm{7.4}), 6 \mathrm{~mm} \mathrm{MgCl}_{2}, 6 \mathrm{~mm}$ 2-mercaptoethanol, $10 \mu \mathrm{g}$ of bovine serum albumin (BSA), 2 units of Bam $\mathrm{H}-1$, and 1-2 $\mu \mathrm{g}$ of leptospiral DNA. Digestions with Hind III were made at $37^{\circ} \mathrm{C}$ for $1 \mathrm{~h}$ in $100 \mu \mathrm{l}$ of a solution

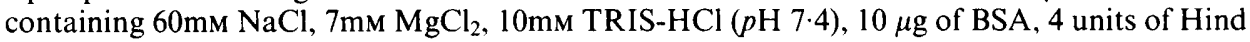
III, and $1-2 \mu \mathrm{g}$ of leptospiral DNA.

TABLE

Bacterial strains

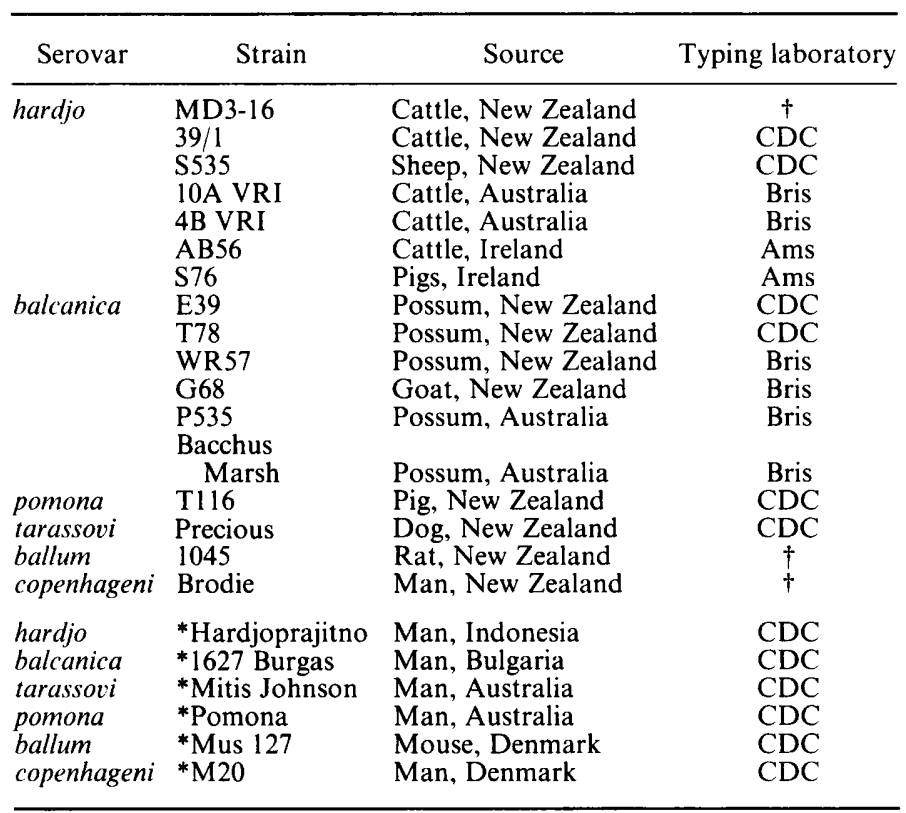

$\mathrm{CDC}=$ Center for Disease Control, Atlanta, GA 30333, USA; Bris = Leptospirosis Reference Laboratory, Department of Health, 63 George Street, Brisbane, Queensland 4000, Australia; Ams = WHO Reference Laboratory,

Royal Tropical Institute, Mauritskade 63, Amsterdam, Netherlands.

* Reference strains; all others were field strains.

+ Typed in this laboratory to serogroup only. 


\section{RESULTS}

Fig. 1 shows a comparison of strains of hardjo from New Zealand, Australia, and Northern Ireland, made by means of the enzyme Eco $R_{1}$. The patterns produced for all six strains were identical. The enzymes Bam $\mathrm{H}-1$ and Hind III each produced patterns differing from that produced by $\mathrm{EcoR}_{1}$, but did not show any differences between the six strains (not illustrated). However, the laboratory strain Hardjoprajitno, used as the type strain by reference laboratories for the agglutinin-absorption test, differed from a field strain of hardjo (fig. 3).

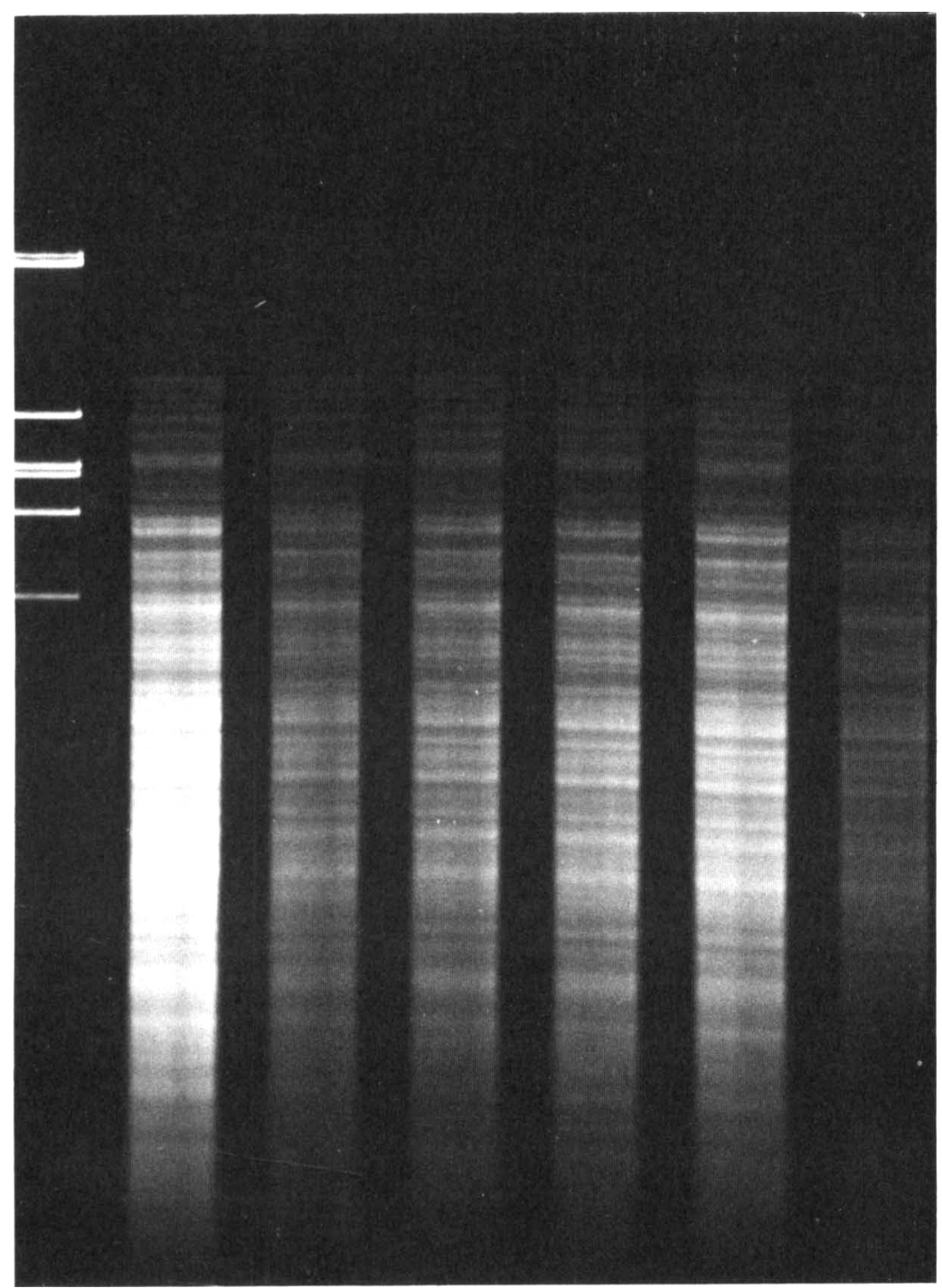

FIG. 1-A comparison of field strains of serovar hardjo from New Zealand, Australia, and Northern Ireland by means of Eco $R_{1}$ restriction endonuclease. From left to right: bacteriophage $\lambda D N A ;$ New Zealand strains 39/1 and S535; Australian strains 10A VRI and 4B VRI; Northern Ireland strains A B56 and S76. 


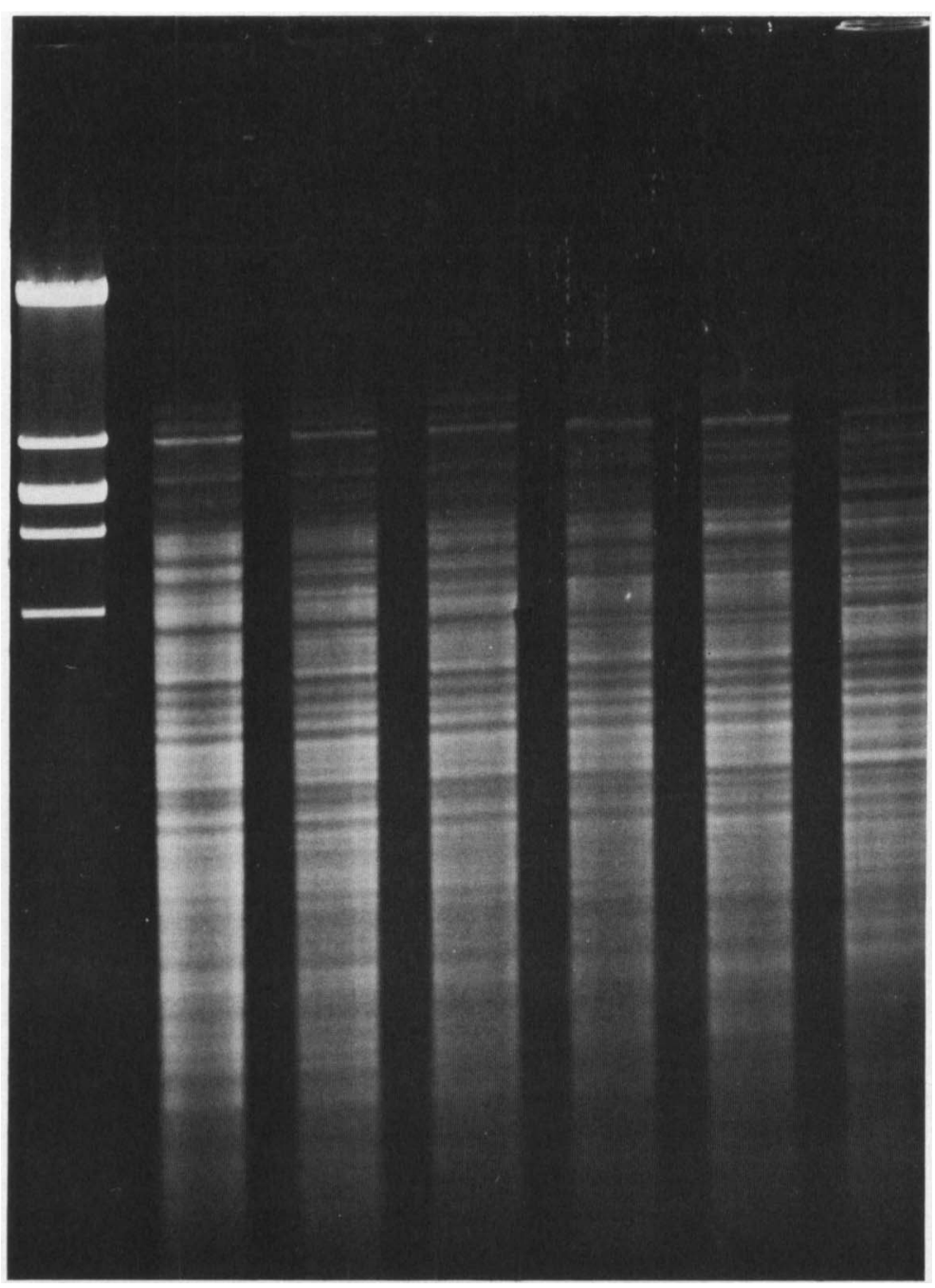

Fig. 2-A comparison of strains of serovar balcanica isolated in New Zealand and Australia, together with the reference strain, by means of Eco $R_{1}$ restriction endonuclease. From left to right: bacteriophage גDNA, T78, WR57, G68, P535, Bacchus Marsh, 1627 Burgas.

A comparison of balcanica strains from New Zealand and from Australia by means of EcoR 1 showed slight differences (fig. 2); but much greater differences were seen between the patterns produced by a reference strain (1627 Burgas) and field strain of balcanica. The differences between the reference strain and a field strain of balcanica can be seen again in fig. 3 .

The tarassovi reference strain Mitis Johnson differed strikingly from a tarassovi strain isolated from the field in New Zealand (fig. 3).

Examination of pomona revealed only a minor difference between the reference and field strain (fig. 4); no differences could be detected between the field and reference strains of copenhageni and ballum. 


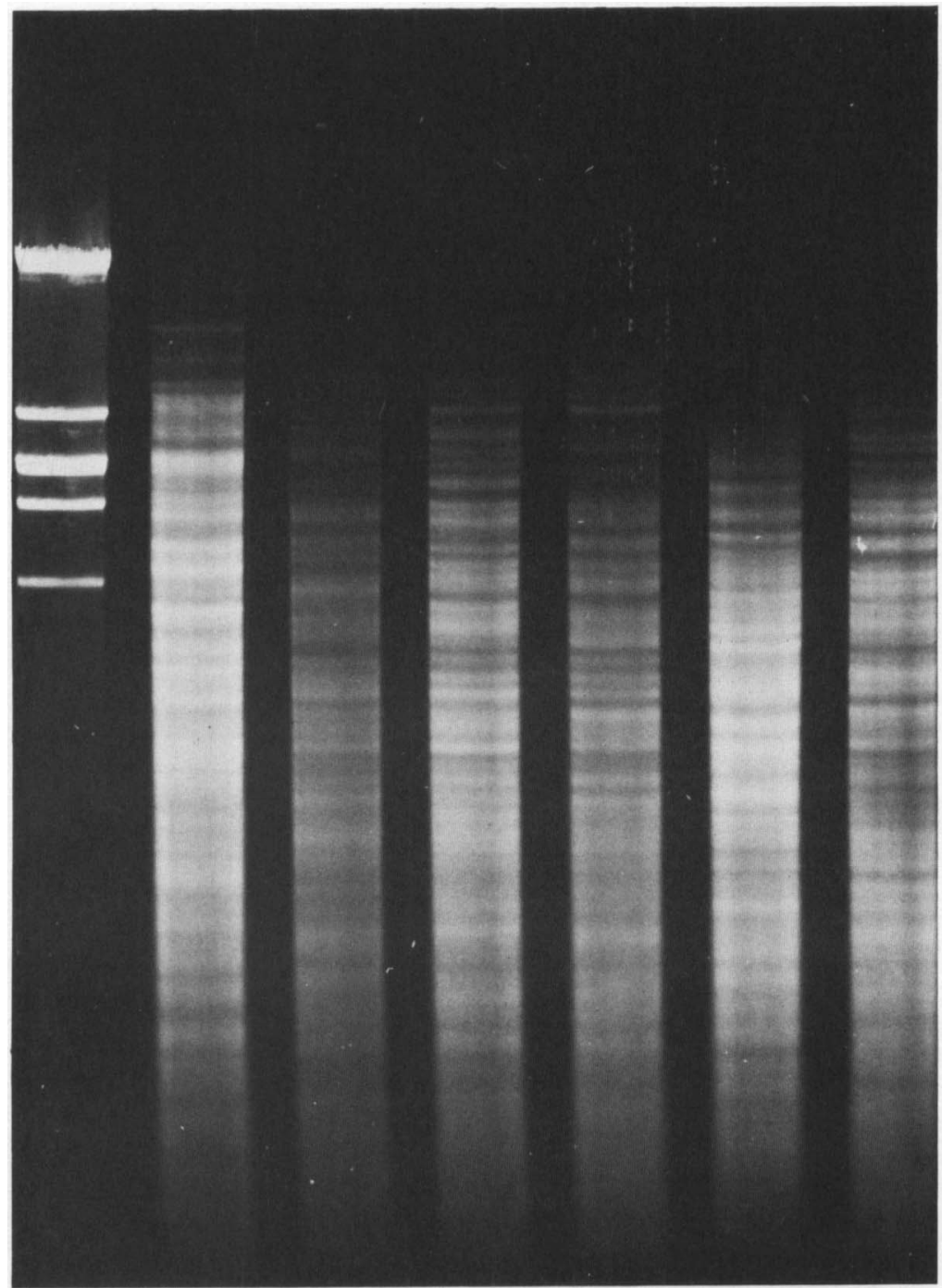

FIG. 3.-A comparison of reference and field strains of serovars hardjo, balcanica and tarassovi by means of Eco $R_{1}$ restriction endonuclease. From left to right: bacteriophage $\lambda D N A$; hardjo strains Hardjoprajitno and MD3-16; balcanica strains 1627 Burgas and E39; tarassovi strains Mitis Johnson and Precious.

\section{DisCUSSION}

This study shows that leptospires typed serologically as hardjo, from cattle, sheep, goats, and pigs in different parts of the world are indistinguishable from one another by BRENDA. This extends our previous observation that the DNA fragment patterns derived from various hardjo strains from New Zealand are identical (Marshall et al., 1981). These field strains of hardjo have, however, a completely different fragment pattern from that of the hardjo reference strain Hardjoprajitno. As a precaution we analysed the DNA of the Hardjoprajitno strain from stocks held at two recognised 


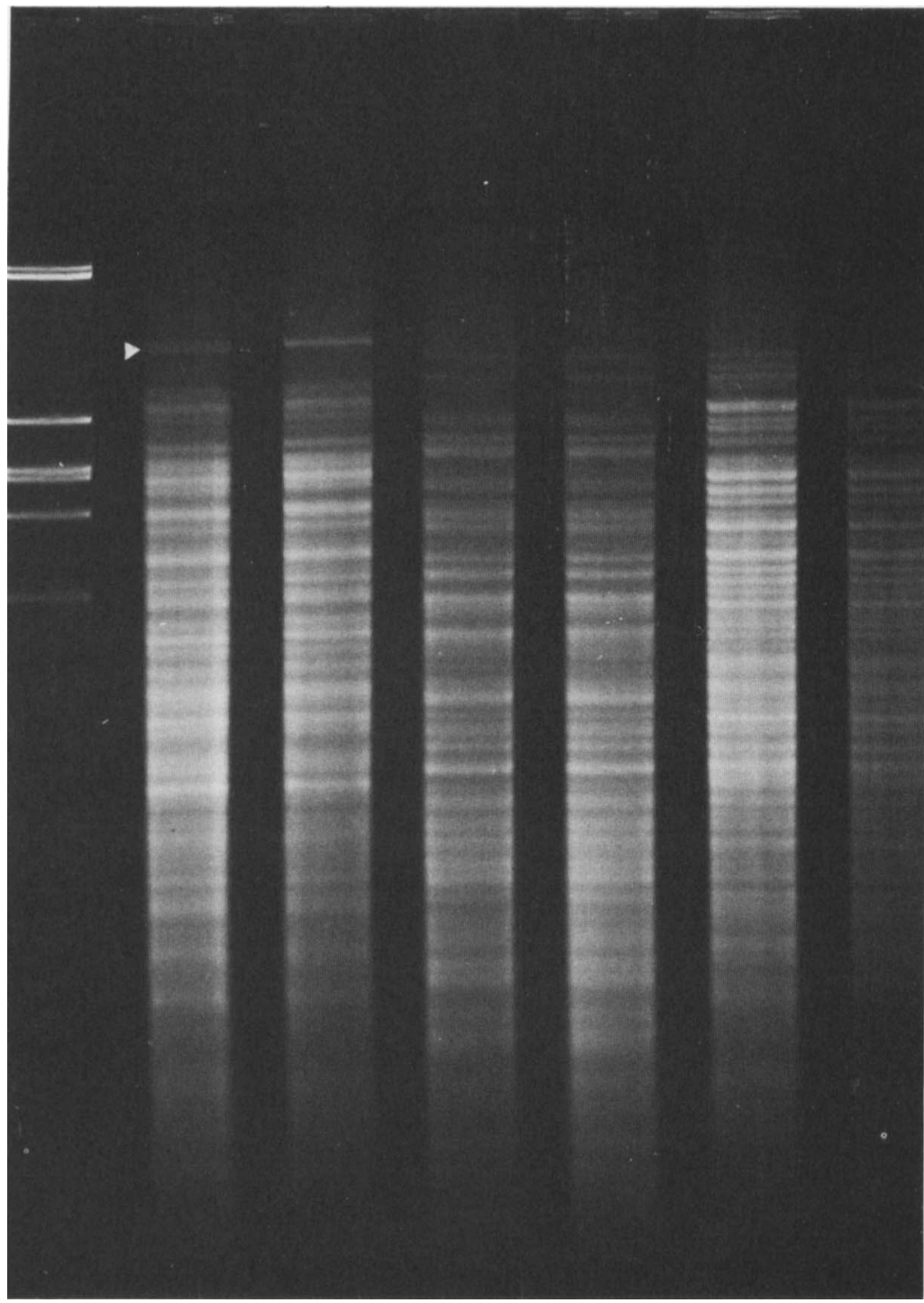

FIG. 4.-A comparison of reference and field strains of serovars pomona, ballum and copenhageni by means of EcoR $R_{1}$ restriction endonuclease. From left to right: bacteriophage $\lambda D N A ;$ pomona strains Pomona and T1 16; ballum strains Mus 127 and 1045; copenhageni strains M20 and Brodie. The arrow marks the position of an extra band seen in the laboratory strain of pomona, which is not seen in the field strain.

reference laboratories and found these two reference strains to be identical (not shown). The degree of difference between hardjo field strains on the one hand and the Hardjoprajitno strain on the other is of the same order as that between different leptospiral reference serovars (Marshall et al., 1981). Even so, the Hardjoprajitno strain shares antigens with field isolates of hardjo and is used in reference laboratories for differentiating them from other members of the Hebdomadis serogroup. Because the Hardjoprajitno strain was isolated from a plantation worker in Sumatra (Wolff, 
1953) and all other strains of hardjo we have examined have been from domestic animals in other countries, we suggest that the two hardjo types probably occupy different ecological niches.

Although unlikely, it could be argued that passage of hardjo in man alters the bacterial DNA, giving rise to a pattern resembling that of the Hardjoprajitno strain. We have analysed three New Zealand human hardjo strains (not shown) and found them indistinguishable from the field strains examined in the present study. Similarly, in New Zealand, pomona strains isolated from man are indistinguishable from those isolated from pigs and cattle.

The BRENDA method has also shown that the balcanica reference strain, 1627 Burgas, differs strikingly from New Zealand and Australian possum strains. The Burgas strain was isolated from a human patient in Bulgaria (Babudieri and Mateev, 1961), but its source was never found. It is unlikely to have been the possum (Trichosurus vulpecula) because this species is confined, at least in the wild habitat, to Australasia. Some other animal or animals must act as the reservoir of balcanica strains of the 1627 Burgas type in Eastern Europe. Balcanica has been isolated from domestic animals in that region (Semenova, Soloshenko and Ananin, 1965; Matveeva et al., 1977), but whether they act as reservoir hosts is not known. We are endeavouring to obtain such isolates in order to compare them with 1627 Burgas and the possum isolates.

A comparison of balcanica isolates from the New Zealand possum with those from Australia revealed minor differences. They were associated with only two or three bands in a total of hundreds and we believe they will not affect the usefulness of BRENDA in enabling new isolates to be placed in the current serovar classification scheme. They may even be useful as epidemiological markers and may reflect virulence, host range, or other differences between strains.

The minor differences between New Zealand and Australian balcanica isolates are interesting from another point of view. The possum is not native to New Zealand but was introduced from the island of Tasmania and State of Victoria, Australia, in a series of importations during 1837-1924. The Australian strains we examined were both from the State of Victoria. The differences between the New Zealand and Australian strains may not have arisen since 1924 but may reflect strain differences existing at the time of introduction. It is even possible that the strains we examined were all originally from Tasmanian possums.

A New Zealand isolate of tarassovi was found to differ from the reference strain, Mitis Johnson. Although we have yet to compare other field strains, we suggest that organisms typed as tarassovi by the agglutinin-absorption technique do not constitute a homogeneous group.

A one-band difference in fragment patterns occurred between the reference strain and a New Zealand strain of serovar pomona but this minor difference did not interfere with the identification of the field strain. No differences were seen between the reference strains of copenhageni and ballum and corresponding New Zealand field isolates.

We have so far catalogued restriction-endonuclease patterns for 33 different reference serovars obtained from either the Center for Disease Control, Atlanta, USA or the Leptospirosis Reference Laboratory, Brisbane, or both. All patterns are unique to each serovar and when more than one representative of a reference serovar has been 
analysed the patterns have been found to be identical. The hardjo, balcanica and tarassovi field isolates described here do not resemble any of the 33 reference strain DNA patterns so far examined.

The present study shows that some serovars of Leptospira interrogans can be subdivided by means of BRENDA. These subdivisions are probably correlated with epidemiological relationships between strains and their hosts; this may necessitate the nomination of new reference strains to represent these subtypes within serovars hardjo, balcanica and tarassovi.

We are indebted to Drs W. A. Ellis, N. D. Stallman, and B. Linehan for supplying some of the leptospiral strains used in this investigation.

\section{REFERENCES}

Babudieri, B. and Mateev, D. 1961. Studies serologico di alcuni ceppi bulgari di leptospire. Rendiconti dell'Istituto Superiori di Sanità, 24, 614-622.

Marshall, R. B., Wilton, B. E. AND Robinson, A. J. 1981. Identification of leptospira serovars by restriction-endonuclease analysis. Journal of Medical Microbiology, 14, 163-166.

Matveeva, A. A., Sakharova, P. U., Sharban, E. K., and Dragomir, A. V. 1977. Etiologiya leptospiroza u zhivotnukh. Veterinariya, 1, 61-63.

Miller, J. H. 1972. Experiments in molecular genetics, Cold Spring Harbour Laboratories, New York, p. 331.

Semenova, L. P., Soloshenko, I. Z. And Ananin, V. V. 1965. Leptospiry gruppy Hebdomadis. III. Obnaruzhenie V Sovetskom Soyuze podtipa L. sejroe balcanica. Zhurnal Mikrobiologii, Epidemiologii i Immunobiologii, 42 (4), 61-64.

TanaKa, T. AND Weisblum, B. 1975. Construction of a colicin El-R Factor composite plasmid in vitro: means for amplification of deoxyribonucleic acid. Journal of Bacteriology, 121, $354-362$.

WoLfF, J. W. 1953. The classification of pathogenic leptospires. In Walter Reed Army Medical Center and Army Medical Service Graduate School Symposium on the leptospires, Dec. 1952, Medical Science Publication no. 1, US Government Printing Office, Washington, pp. 174-185.

YounghuSBAND, H. B. AND BeLLETt, A. J. D. 1971. Mature form of the deoxyribonucleic acid from chick embryo lethal orphan virus. Journal of Virology, 8, 265-274. 